\title{
Analysis of the tsunami generated by the 2007 Noto Hanto earthquake
}

\author{
Yuichiro Tanioka \\ Institute of Seismology and Volcanology, Hokkaido University, N10W8 Kita-Ku, Sapporo 080-0610, Japan
}

(Received June 30, 2007; Revised November 2, 2007; Accepted November 13, 2007; Online published February 19, 2008)

\begin{abstract}
The 2007 Noto Hanto earthquake generated a small tsunami that was recorded at several tide gauge stations along the coast of the Japan Sea. The most important feature of this tsunami is that two waveforms recorded at the Wajima and Noto tide gauge stations, which are located $30 \mathrm{~km}$ apart, showed very different later phases-the large later phases recorded at Noto were not observed at Wajima. Numerical simulation of the tsunami indicated that the difference was caused by the shallow water bathymetry around the Noto peninsula. The large tsunami that was amplified at a few tens of kilometers off the north coast of the Noto peninsula propagated towards the Noto tide gauge station, but not towards the Wajima station. This study indicates that the propagation of a tsunami caused by a shallow earthquake beneath a coastal area is significantly affected by the local bathymetry. A comparison of the observed and computed tsunami waveforms indicated that the slip amount of the fault was $0.8 \mathrm{~m}$. The seismic moment of the Noto Hanto earthquake was calculated to be $0.94 \times 10^{19} \mathrm{~N} \mathrm{~m}\left(M_{\mathrm{w}} 6.6\right)$.
\end{abstract}

Key words: 2007 Noto Hanto earthquake, tsunami numerical simulation.

\section{Introduction}

On 25 March 2007, a large earthquake occurred off the northwest coast of the Noto peninsula in Japan. The Japan Meteorological Agency (JMA) called it the Noto Hanto earthquake and estimated the source parameters as follows: origin time, 9:42 (JST); epicenter, $37.22^{\circ} \mathrm{N}, 136.685^{\circ} \mathrm{E}$; depth, $11 \mathrm{~km}$; JMA estimated magnitude, $M_{\mathrm{j}} 6.9$. The seismic moment in the Global CMT catalog is $1.38 \times 10^{19} \mathrm{~N} \mathrm{~m}$ $\left(M_{\mathrm{w}} 6.7\right)$. The Noto Hanto earthquake killed one person and caused significant damage near the source area. The focal mechanism of the earthquake, estimated using the teleseismic body waves (Yamanaka, 2007), indicates a reversetype faulting with a right-lateral component (strike $=60^{\circ}$, $\operatorname{dip}=72^{\circ}$, rake $=120^{\circ}$ ). The Noto Hanto earthquake also generated a small tsunami because a part of the source area reached beneath the Japan Sea (Fig. 1). This tsunami was observed at several tide gauge stations along the Japan Sea (Japan Meteorological Agency, 2007).

The most interesting observed feature of this tsunami is that among the tsunami waveforms recorded at the Wajima and Noto tide gauge stations, which are located $30 \mathrm{~km}$ apart, two showed very different later phases (Fig. 2): a large later phase observed at the Noto station was not observed at the Wajima station. In this paper, we attempt to determine the generation mechanism of the large later phase recorded at the Noto tide gauge station by carrying out a numerical simulation analysis of the tsunami. We also compare the observed and computed tsunami waveforms to estimate the seismic moment of the earthquake.

Copyright (c) The Society of Geomagnetism and Earth, Planetary and Space Sciences (SGEPSS); The Seismological Society of Japan; The Volcanological Society of Japan; The Geodetic Society of Japan; The Japanese Society for Planetary Sciences; TERRAPUB.

\section{Data and Method for Tsunami Computation}

The tsunami waveforms recorded at two tide gauge stations, Wajima and Noto, are used in our analysis (Fig. 2). The real-time tide gauge data at the Noto and Wajima stations were provided by the JMA and Geographical Survey Institute (GSI), respectively, through their homepages. At Wajima, the first tsunami wave had an amplitude of $4 \mathrm{~cm}$ and arrived about $30 \mathrm{~min}$ after the origin time of the earthquake. At Noto, the first tsunami wave had an amplitude of $6 \mathrm{~cm}$ and arrived about $40 \mathrm{~min}$ after the origin time, while the large later tsunami with amplitude of $18 \mathrm{~cm}$ arrived about $90 \mathrm{~min}$ after the origin time of the earthquake. A rectangular fault model (Fig. 1), which was estimated by the Geographical Survey Institute (2007) using GPS data, was used to compute the tsunami. The depth of the top edge of the rectangular fault model is $1 \mathrm{~km}$, the fault length and width are 21 and $14 \mathrm{~km}$, respectively, and the strike, dip, and rake of the fault are $55^{\circ}, 63^{\circ}$, and $137^{\circ}$, respectively.

The vertical seafloor displacement from the rectangular fault model was computed using Okada's (1985) equations and used as an initial condition of tsunami numerical simulation. Finite-difference computations of the linear longwave equations (see Johnson, 1998) were carried out. The total reflection boundary condition was used at the coast. The 30-s grid bathymetry data produced by the Marine Information Research Center in the Japan Hydrographic Association were used. The time step of the computation was $1 \mathrm{~s}$ to satisfy a stability condition of the finite-difference computation. A slip amount of the rectangular fault (Fig. 1) was estimated by comparing the observed and computed tsunami amplitudes of the first arrived tsunami wave at the two tide gauge stations. 


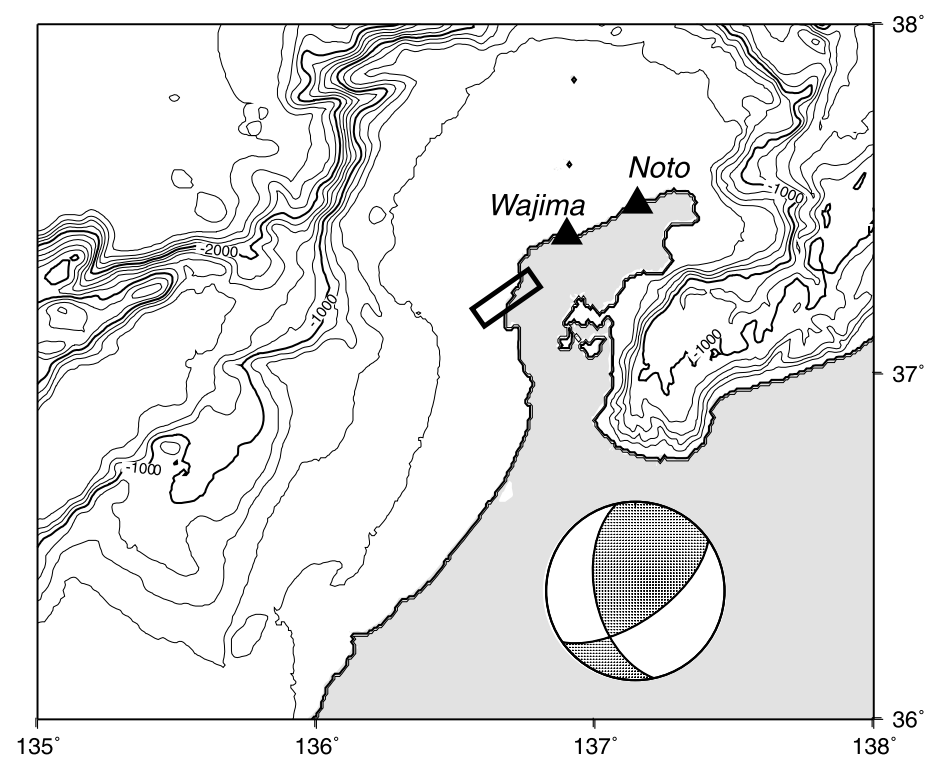

Fig. 1. Map near the source area of the Noto Hanto earthquake. Triangles show the locations of two the tide gauge stations, Noto and Wajima. The rectangle indicates the fault model estimated by Geographical Survey Institute (2007). The focal mechanism of the earthquake used in this study is also shown.

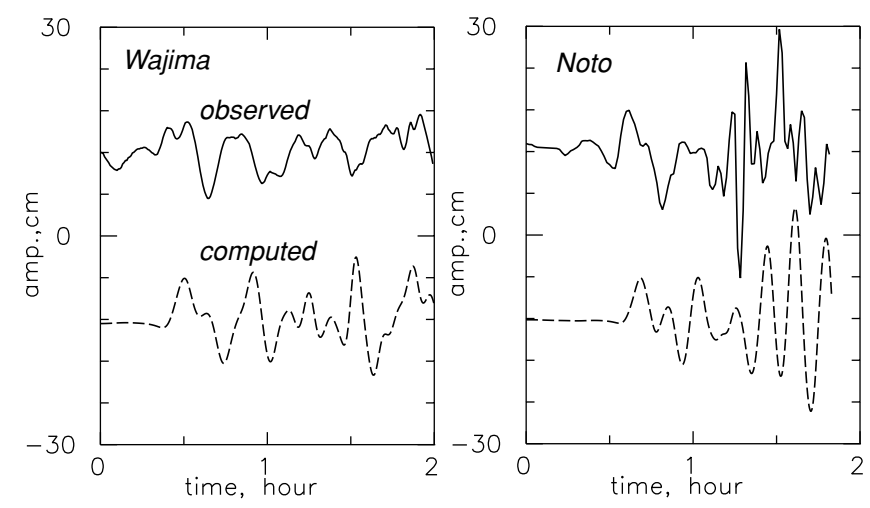

Fig. 2. Comparison of the observed (solid lines) and computed (dashed lines) tsunami waveforms at the tide gauge stations at Wajima and Noto.

\section{Result}

The comparison of the observed and computed tsunami waveforms at two tide gauges, Wajima and Noto, is shown in Fig. 2. The slip amount was estimated to be $0.8 \mathrm{~m}$. The seismic moment of the 2007 Noto Hanto earthquake was calculated as $0.94 \times 10^{19} \mathrm{~N} \mathrm{~m}\left(M_{\mathrm{w}} 6.6\right)$ by assuming the rigidity of $4 \times 10^{10} \mathrm{~N} / \mathrm{m}^{2}$. Our estimate of the seismic moment is similar to the other estimates, such as the Global CMT estimate of $1.38 \times 10^{19} \mathrm{~N} \mathrm{~m}\left(M_{\mathrm{w}} 6.7\right)$, indicating that the tsunami generation of this earthquake was not unusual. Although the period of large later phases observed at the Noto tide gauge was shorter than the computed ones, the amplitude of the observed and computed later phases were similar.

Figure 3 shows the bathymetry off the coast of the Noto peninsula region and snapshots of the computed tsunami at 10 -min intervals up to $80 \mathrm{~min}$ after the origin time of the earthquake. A large and shallow continental shelf exists around the Noto peninsula. At 30 min post-earthquake, the first tsunami arrived at the Wajima tide gauge (Figs. 2 and 3). A larger tsunami propagated through a shallow region around the Noto peninsula (Fig. 3(a)). When the tsunami reached the deep sea, it became smaller and propagated faster (Fig. 3(b)). The figure shows that a large part of the tsunami energy was trapped in the shallow region. This type of tsunami wave was called an edge wave and has been studied in other tsunamis by Gonzalez et al. (1995) and Tanioka and Katsumata (2007). At $40 \mathrm{~min}$, the first wave arrived at the Noto tide gauge (Figs. 2 and 3). The tsunami was amplified a few tens of kilometers north of the Noto peninsula where there is a large slope between the shallow sea and deep sea regions (Fig. 3(c)). The tsunami wave was refracted above the slope, and the resulting large tsunami propagated towards the east. At $50 \mathrm{~min}$, the first wave has already passed the Noto tide gauge station. The large tsunami amplified the north of the Noto peninsula started to propagate towards the south along the shallow sea off the Noto peninsula and became even larger (Fig. 3(d)). At 60 or $70 \mathrm{~min}$, the large tsunami that had been amplified north of the peninsula continuously propagated towards the south and eventually reached the Noto tide gauge station (Fig. 3(f)). However, that large tsunami did not propagate towards the Wajima tide gauge station, which is located about $30 \mathrm{~km}$ west of the Noto tide gauge. 

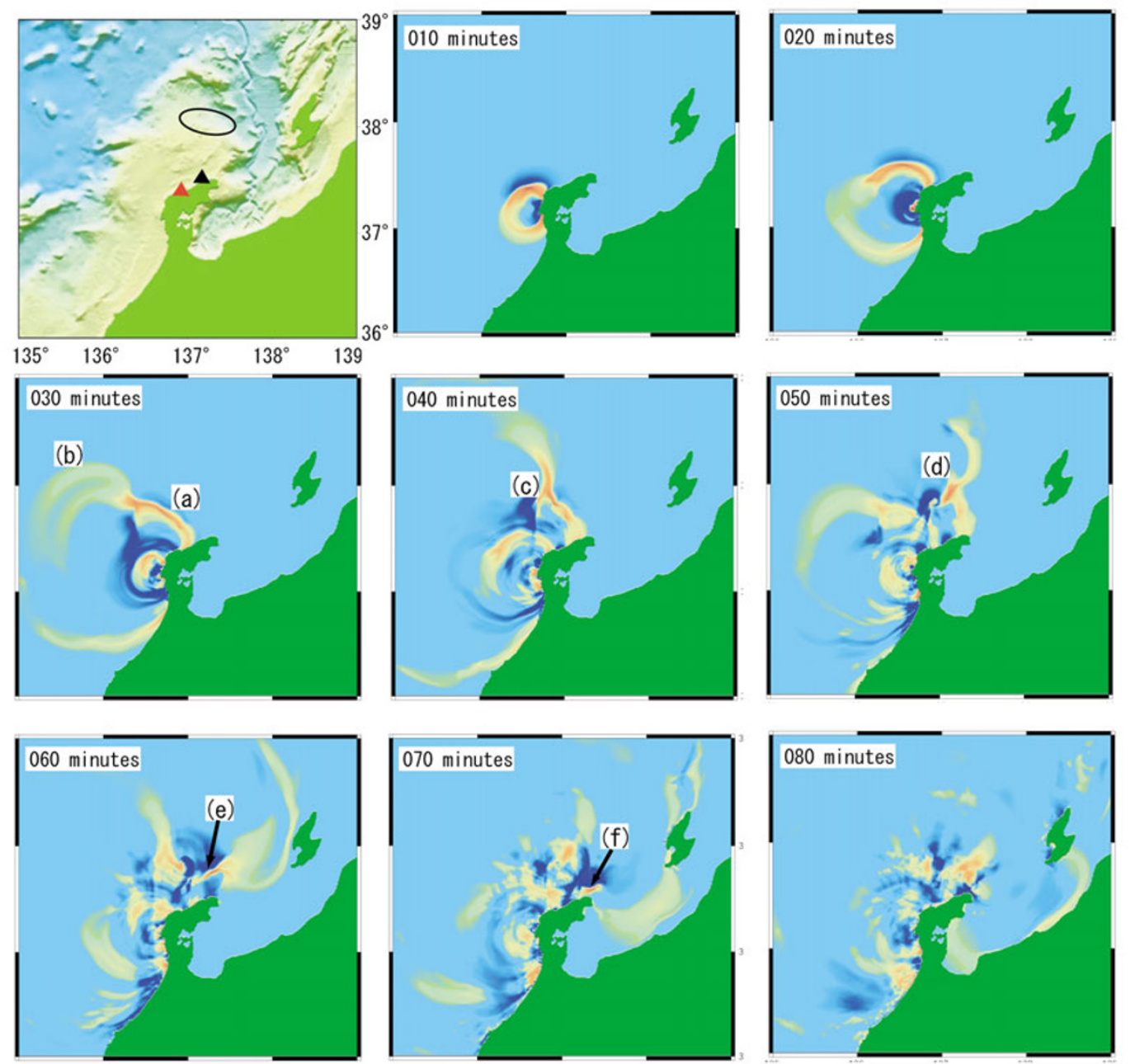

Fig. 3. The bathymetry off the Noto peninsula and eight snapshots of the computed tsunami at 10, 20, 30, 40, 50, 60, 70, and 80 min after the origin time of the earthquake. Yellow or red indicates the positive waves and blue denotes the negative waves. Black and red triangles show the location of the Noto and Wajima tide gauge stations, respectively. The ellipsoid shows a large slope between the shallow sea and deep sea regions.

\section{Discussion and Conclusions}

The Noto Hanto earthquake ruptured the shallow fault located beneath the Japan Sea and the Noto peninsula (Fig. 1), resulting in the tsunamigenic vertical coseismic deformation within the shallow water region around the Noto peninsula. In this case, the bathymetry around the Noto peninsula significantly affected the propagation of the tsunami. The large later phases observed at Noto tide gauge station were not observed at the Wajima tide gauge station. The numerical simulation of the tsunami indicated that the difference was caused by the shallow water around the Noto peninsula. The tsunami was amplified a few tens of kilometers north off the coast of Noto peninsula. It propagated towards the Noto tide gauge station and was recorded as the large later phase. The large tsunami did not propagate towards the Wajima gauge station and, therefore, no large later phase was recorded there.

This study suggests that the propagation of a tsunami caused by a shallow earthquake beneath a coastal area is significantly affected by the local bathymetry. It is therefore important to estimate the maximum tsunami amplitude along the coast using a detailed tsunami simulation.
Acknowledgments. I thank the Japan Meteorological Agency and Geographical Survey Institute for providing the real time tide gauge data through an internet. I also thank Dr. Kenji Satake and Dr. Kenji Hirata for their helpful comments.

\section{References}

Geographical Survey Institute, Related repots for the 2007 Noto Hanto earthquake, http://www.gsi.go.jp/BOUSAI/isikawa/index.html, 2007 (in Japanese).

Gonzalez, I. F., K. Satake, E. F. Boss, and H. O. Mofjeld, Edge wave and non-trapped modes of the 25 April 1992 Cape Mendocino Tsunami, Pure Appl. Geophys., 144, 409-426, 1995.

Japan Meteorological Agency, Evaluation of the 2007 Noto Hanto earthquake, http://www.jishin.go.jp/main/chousa/07mar_noto/index.htm, 2007 (in Japanese).

Johnson, J. M., Heterogeneous coupling along Alaska-Aleutians as inferred from tsunami, seismic, and geodetic inversions, Adv. Geophys., 39, 1-110, 1998.

Okada, Y., Surface deformation due to shear and tensile faults in a halfspace, Bull. Seismol. Soc. Am., 75, 1135-1154, 1985.

Tanioka, Y. and K. Katsumata, Tsunami generated by the 2004 Kushiro-oki earthquake, Earth Planets Space, 59, e1-e3, 2007.

Yamanaka, K., RSVD seismology notes, http://www.eri.u-tokyo.ac.jp/ sanchu/Seismo_Note/2007/RSVD1.html, 2007 (in Japanese).

Y. Tanioka (e-mail: tanioka@mail.sci.hokudai.ac.jp) 